\title{
Proteomic profiling of peripheral blood neutrophils identifies two inflammatory phenotypes in stable COPD patients
}

Adèle Lo Tam Loi', Susan Hoonhorst ${ }^{2}$, Corneli van Aalst ${ }^{1}$, Jeroen Langereis ${ }^{1}$, Vera Kamp ${ }^{1}$, Simone Sluis-Eising ${ }^{1}$, Nick ten Hacken ${ }^{2}$, Jan-Willem Lammers ${ }^{1}$ and Leo Koenderman ${ }^{1,3^{*}}$

\begin{abstract}
Background: COPD is a heterogeneous chronic inflammatory disease of the airways and it is well accepted that the GOLD classification does not fully represent the complex clinical manifestations of COPD and this classification therefore is not well suited for phenotyping of individual patients with COPD. Besides the chronic inflammation in the lung compartment, there is also a systemic inflammation present in COPD patients. This systemic inflammation is associated with elevated levels of cytokines in the peripheral blood, but the precise composition is unknown. Therefore, differences in phenotype of peripheral blood neutrophils in vivo could be used as a read out for the overall systemic inflammation in COPD.
\end{abstract}

Method: Our aim was to utilize an unsupervised method to assess the proteomic profile of peripheral neutrophils of stable COPD patients and healthy age matched controls to find potential differences in these profiles as read-out of inflammatory phenotypes. We performed fluorescence two-dimensional difference gel electrophoresis with the lysates of peripheral neutrophils of controls and stable COPD patients.

Results: We identified two groups of COPD patients based on the differentially regulated proteins and hierarchical clustering whereas there was no difference in lung function between these two COPD groups. The neutrophils from one of the COPD groups were less responsive to bacterial peptide $\mathrm{N}$-formyl-methionyl-leucyl-phenylalanine (fMLF).

Conclusion: This illustrates that systemic inflammatory signals do not necessarily correlate with the GOLD classification and that inflammatory phenotyping can significantly add in an improved diagnosis of single COPD patients.

Trial registration: Clinicaltrials.gov: NCT00807469 registered December 11th 2008

Keywords: COPD, Proteomics profile, Neutrophil, Systemic inflammation, Inflammatory phenotype

\section{Background}

Chronic Obstructive Pulmonary Disease (COPD) is characterized by irreversible airflow limitation [1] and is a leading cause of mortality and morbidity worldwide [2]. Cigarette smoking is the most important risk factor for the

\footnotetext{
* Correspondence: I.koenderman@umcutrecht.nl;

L.Koenderman@umcutrecht.nl

'Departments of Respiratory Medicine, University Medical Center Utrecht, Utrecht, The Netherlands

${ }^{3}$ Department Respiratory Medicine and Laboratory of Translational

Immunology, University Medical Center Utrecht, Heidelberglaan 100, 3583CX

Utrecht, The Netherlands

Full list of author information is available at the end of the article
}

development of COPD in the western world. According to the Global Initiative for Chronic Obstructive Pulmonary Disease (GOLD) the diagnosis and severity of COPD is assessed using lung function measurements: Forced Expiratory Volume (FEV1) and Forced Vital Capacity (FVC) [3, 4]. It is well accepted that these spirometry measurements are insufficient, mainly because spirometry data alone poorly correlate with symptoms and health status $[5,6]$.

Many studies have been focused on the identification of disease phenotypes in COPD and have searched for individual and/or combined biomarkers using data from 
exhaled breath condensate [7], lung biopsies [8-10], induced sputum [11], plasma [12-14] and bronchoalveolar lavage (BAL) fluid [15]. Unfortunately, bonchoscopy to obtain lung tissue and BAL fluid and to a lesser extent induced sputum are invasive procedures and are therefore difficult to perform regularly in COPD patients especially in the more severe phenotypes. Therefore, there is an unmet clinical need for objective disease markers identifying COPD phenotypes that can be obtained with non invasive methods.

The airflow limitation in COPD is usually progressive and is associated with an abnormal inflammatory response in the lungs. This inflammation in the lung is characterized by an accumulation of neutrophils, macrophages and lymphocytes [16]. Besides the inflammation in the lung there is also a systemic inflammation that is normally illustrated by elevated levels of cytokines (TNF $\alpha$, IL-8) and CRP in the peripheral blood of COPD patients $[17,18]$. Oudijk et al. [19] have shown that peripheral blood neutrophils from COPD patients were characterized by modulated gene expression of IL-1 $\beta$, IL-1R $\alpha$, MIP-1 $\beta$ and CD83 [19], which correlated with a decreased FEV1. We have shown that pro-inflammatory cytokines such as GM-CSF and TNFo can both synergize and antagonize inflammatory signaling pathways in neutrophils [20]. Therefore, measurements of individual cytokines using multiplex assays without determining their natural modulators in clinical samples could lead to wrong conclusions. And, therefore, modulation of protein expression in peripheral blood neutrophils as read-out of the combined action of pro- and antiinflammatory cytokines on leukocytes could be a better approach to measure systemic inflammation in COPD patients.

We collected peripheral blood neutrophils from COPD patients to perform proteomics analysis. We hypothesize that the net result of multiple cytokines on the change in phenotype of peripheral blood neutrophils in vivo can be used as a read out for the overall inflammatory status of the COPD patients. We used the unbiased fluorescence two-dimensional (2D) difference gel electrophoresis (DIGE) method to analyze protein expression of peripheral blood neutrophils from COPD patients and healthy aged matched controls.

\section{Methods}

\section{Patients and healthy controls}

We included 41 stable COPD patients (age 40-75 years) with a smoking history of more than 10 pack years and a ratio of FEV1 to forced vital capacity (FVC) below $70 \%$ after bronchodilator use, as described by the global initiative for chronic obstructive lung disease (GOLD) [21]. COPD patients with a history of other inflammatory diseases, acute pulmonary disease or other infections, treatment with antibiotics or corticosteroids 8 weeks to inclusion, recent diagnosis of cancer and a history of asthma were excluded. Control subjects were healthy age-matched subjects with normal lung function and no medical history of pulmonary disease. This study was approved by the medical ethical committee and all study subjects provided written informed consent. This study is based on data collected as part of a bi-center cross-sectional study performed by University Medical Centers of Utrecht and Groningen, with trial register numbers NCT00850863 and NCT00807469 (www.clinicaltrials.gov).

\section{Reagents and antibodies}

Ficoll-Paque was obtained from GE Healthcare (Uppsala, Sweden). Human Serum Albumin (HSA) was from Sanquin (Amsterdam, the Netherlands). HEPES-buffered RPMI 1640 was from Invitrogen (Carlsbad, CA, USA). Dihydrorhodamine 123 (DHR) was purchased from Sigma Aldrich (St. Louis, MO, USA) and dissolved in DMSO at a concentration of $3,33 \mathrm{mg} / \mathrm{ml}$ and stored at $-20^{\circ} \mathrm{C}$. Platelet Activating Factor (PAF) and PMLF were purchased from Sigma Chemical Co (St. Louis, MO, USA). The VIM12 (CD11b, Mac-1, IgG1) was obtained from Caltag Invitrogen (Carlsbad, CA, USA). For flow cytometry staining we used the antibodies CD18 (clone L130); CD15 (clone MMA); CD32 (clone FLI8.26), CD35 (clone E11), CD44 (clone 515), CD63 (clone H5C6) and CD16 (clone 3G8) obtained from BD Pharmingen (San Diego, CA, USA). CD11b (clone 2LPM19c) was from DAKO (Copenhagen, Denmark), CD66b (clone 80H3) was from Cytognos (Salamanca, Spain), CXCR1 (clone 42705), CXCR2 (clone 48311) and CD45 (clone 2D1) were from R\&D systems (Europe, UK) and CD64 (clone 10.1) was from AbD Serotec (Oxford, UK). CD29 (clone N29) was purchased from Millipore. All other chemicals were reagent grade.

\section{Granulocyte isolation}

Granulocytes were isolated from whole blood anticoagulated with sodium-heparin from COPD patients or agematched healthy control subjects. Blood was diluted 2.5:1 with PBS containing trisodium citrate $(0.4 \% w / v, \mathrm{pH} 7.4)$ and human pasteurized plasma-protein solution $(4 \mathrm{~g} / \mathrm{L})$. The granulocytes were separated from the mononuclear cells by centrifugation using Ficoll-Paque. Erythrocytes were lysed in isotonic ice-cold $\mathrm{NH}_{4} \mathrm{Cl}$ solution $(8.3 \mathrm{~g} / \mathrm{L}$ $\mathrm{NH}_{4} \mathrm{Cl}, 1 \mathrm{~g} / \mathrm{L} \mathrm{KHCO}_{3}$ and $37 \mathrm{mg} / \mathrm{L}$ EDTA) followed by centrifugation at $4{ }^{\circ} \mathrm{C}$. After isolation, granulocytes were washed in PBS containing trisodium citrate $(0.4 \% \mathrm{w} / \mathrm{v}$, $\mathrm{pH}$ 7.4) and human pasteurized plasma-protein solution ( $4 \mathrm{~g} / \mathrm{L}$ ) and resuspended in HEPES buffered RPMI 1640 supplemented with $0.5 \%(w / v)$ HSA. Purity of neutrophils was $>95 \%$ with eosinophils as major contaminant. 


\section{Protein extract preparation}

Neutrophils $\left(5 \times 10^{6} / \mathrm{mL}\right)$ in HEPES buffered RPMI 1640 supplemented with $0.5 \%(\mathrm{w} / \mathrm{v})$ HSA were incubated for $15 \mathrm{~min}$ at $37^{\circ} \mathrm{C}$. Subsequently, neutrophils of COPD patients and healthy age-matched controls were immediately prepared for protein extracts. The neutrophils $\left(1 \times 10^{7} /\right.$ sample $)$ were washed twice with sucrose buffer (0.34 M sucrose, $1 \mathrm{mM}$ EDTA, $10 \mathrm{mM}$ Tris) and lysed in lysis buffer $(10 \mathrm{mM}$ Tris $\mathrm{pH} 7.4,10 \%$ glycerol, $1 \%$ NP40, $50 \mathrm{mM} \mathrm{NaF}, 20 \mathrm{mM}$ tetra-Na pyrophosphate, $1 \mathrm{mM}$ DTT, $2 \mathrm{mM}$ vanadate, $1 \mathrm{mM}$ PMSF, $2 \mathrm{mM}$ DFP and $1 \times$ Complete EDTA-free protease inhibitor cocktail tablet (Roche)). Proteins were precipitated with $80 \%$ acetone and dissolved in labeling buffer (8 M Urea, $2 \mathrm{M}$ Thiourea, 4\% CHAPS, $10 \mathrm{mM}$ Tris $\mathrm{pH} 8.5$ ).

\section{CyDye labeling}

The DIGE technology is an unbiased approach to identify differences in protein expression and the use of an internal standard enables identification of protein differences as small as 10\% [22]. Protein extracts were labeled using the fluorescent cyanine dyes developed for 2DDIGE technology (GE Healthcare) following manufacturer's protocol. Protein extracts $(30 \mu \mathrm{g})$ were labeled with $300 \mathrm{pmol}$ of fluorescent dye (Cy2 or Cy3 or Cy5). Protein samples from COPD patients and healthy agematched control were randomly labeled with $\mathrm{Cy} 3$ or Cy5. To exclude the effects of preferential labeling each dye was used a similar number of times in each group. An internal standard, created by pooling $15 \mu \mathrm{g}$ of each protein sample, was labeled with Cy2. Labeling was stopped by adding lysine and equal volume of $2 \times$ IEF buffer (8 M Urea, $2 \mathrm{M}$ Thiourea, 4\% CHAPS, $300 \mathrm{mM}$ DTT, 1.0\% IPG buffer 3-10NL, 0.004\% Bromophenolblue) to each sample.

\section{D-gel electrophoresis and analysis}

Two protein samples (Cy3 and Cy5) were mixed with the Cy2-labeled internal control. Protein samples were passively rehydrated into $24 \mathrm{~cm} \mathrm{pH} \mathrm{3-10} \mathrm{NL} \mathrm{strips} \mathrm{(GE}$ Healthcare, Uppsala, Sweden) for $10 \mathrm{~h}$ followed by isoelectric focusing using a manifold-equipped IPGphor IEF unit (GE Healthcare) according to the manufacturer's protocol. The cysteine sulfhydryls were reduced with $1.0 \%$ DTT and carbamidomethylated with $2.5 \%$ Iodoacetamide in equilibration buffer (30\% glycerol, 2\% SDS, $6 \mathrm{M}$ urea, $75 \mathrm{mM}$ Tris, $\mathrm{pH}$ 8.8). Second dimensional SDS-PAGE was performed on hand-cast $12 \%$ SDS-PAGE gels using low fluorescence glass plates. Electrophoresis was carried out at 0.2 watts/gel for $2 \mathrm{~h}$ followed by 1 watts/gel until completion using an Ettan DALT-12 unit (GE Healthcare). Gels were scanned using a Typhoon 9410 imager at $100 \mu \mathrm{m}$ resolution (GE Healthcare). Scan settings were optimized for a maximal signal of 85.000 counts. The gel images were cropped using ImageQuantTL 2003 (GE Healthcare), spot detection was performed with DeCyder 7.0 DIA (Difference In-gel Analysis) software (GE Healthcare) and gel images were matched using DeCyder 7.0 BVA (Biological Variation Analysis) software (GE Healthcare). Proteins present in $>70 \%$ of the spot maps were included in the analysis and proteins with an average ratio of at least 1.5 and $p<0.05$ were considered significant.

\section{Flow cytometry analysis}

Blood was collected from COPD patients in sterile collection tubes containing sodium heparin as an anticoagulant. The erythrocytes from the whole blood were lysed with ice-cold $\mathrm{NH}_{4} \mathrm{Cl}$. The leukocytes were washed once with ice cold $\mathrm{NH}_{4} \mathrm{Cl}$ and centrifuged at $4{ }^{\circ} \mathrm{C}$. Hereafter, the cells were washed and resuspended in PBS buffer for FACS analysis in (PBS containing 0.32\% $(w / v)$ sodium citrate and human pasteurized plasma solution $(4 \mathrm{~g} / \mathrm{L}))$. Unstmulated leukocytes $\left(1.25 \times 10^{5}\right.$ cells) were stained with CD11b, CD18, CD15, CD66b, CXCR1, CD64, CD29 and CD32 in combination with CD16 for $30 \mathrm{~min}$ at $4{ }^{\circ} \mathrm{C}$, washed once in PBS buffer and resuspended in PBS buffer. Cells were analyzed on a FACs Calibur flow-cytometer (Becton Dickinson, Mountain View, CA, USA). Neutrophils were identified according to their specific side scatter and forward scatter signals and CD16 expression (for the gating strategy see Fig. 1). The experiments were controlled by staining cells with isotype control antibodies (see e.g. Fig. 5).

For staining with antibodies against the active form of Fc $\gamma$ RII we used the directly FITC-labelled monoclonal phage antibody A17, as described previously [23]. In short, whole blood was stimulated in the presence or absence $10^{-6} \mathrm{M}$ of fMLF for $5 \mathrm{~min}$ at $37^{\circ} \mathrm{C}$. After stimulation the A17 antibody and CD11b PE antibody were added to $50 \mu \mathrm{l}$ whole blood and incubated for $60 \mathrm{~min}$ at $4{ }^{\circ} \mathrm{C}$. After staining erythrocytes were lysed and expression of active Fc $\gamma$ RII (A17) and CD11b were measured on a FACS Calibur (Becton Dickinson, Mountain View, CA, USA).

\section{Respiratory burst assay}

After lysis of the erythrocytes, the leukocytes were washed and resuspended in HEPES buffer (20 mM HEPES, $132 \mathrm{mM} \mathrm{NaCl}, 6 \mathrm{mM} \mathrm{KCl}, 1.2 \mathrm{mM} \mathrm{K} \mathrm{H}_{2} \mathrm{PO}_{4}, 1 \mathrm{mM}$ $\mathrm{MgSO}_{4}$ ), supplemented with $5 \mathrm{mM}$ glucose, $1 \mathrm{mM} \mathrm{CaCl}$, and $0.5 \%(w / v)$ human serum albumin (HSA). The leukocytes $\left(2.0 \times 10^{6}\right.$ cells $\left./ \mathrm{ml}\right)$ were primed with $10^{-6} \mathrm{M}$ PAF at $37^{\circ} \mathrm{C}$. After $2 \mathrm{~min}$ DHR was added to a final concentration of $1 \mu \mathrm{Mol} / \mathrm{L}$ and incubated for $5 \mathrm{~min}$. In some experiments the cells were stimulated with fMLF $\left(10^{-6} \mathrm{M}\right)$ or VIM12 $(10 \mu \mathrm{g} / \mathrm{ml})$ at $37{ }^{\circ} \mathrm{C}$ in the dark. After stimulation 

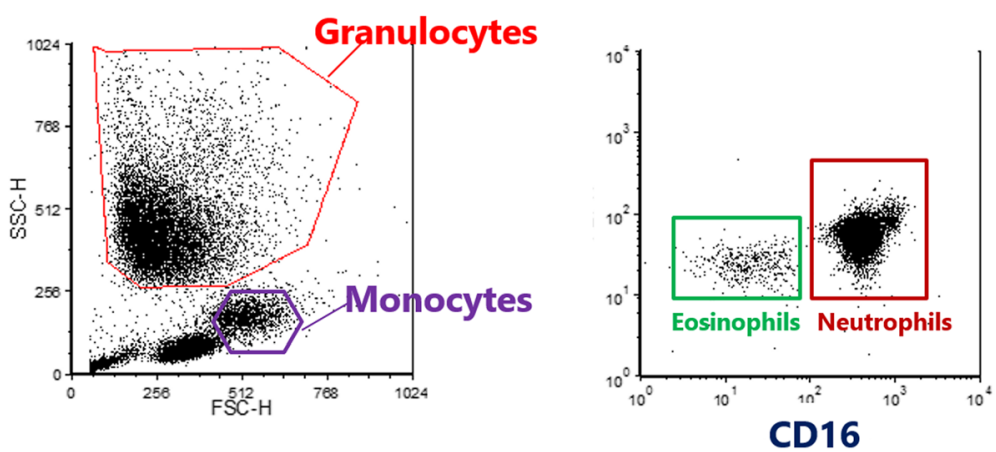

Fig. 1 Flowcytometry gating strategy. Granulocytes and monocytes were identified according to forward and sideward scatter signal. Neutrophils and eosinophils were identified according their CD16 expression

the cells were washed with $3 \mathrm{ml}$ of cold PBS supplemented with $1 \%(w / v)$ HSA and samples were kept at $4{ }^{\circ} \mathrm{C}$ in the dark. The production of reactive oxygen species (ROS) was analyzed with a FACs Calibur flow cytometer (Becton Dickinson, Mountain View, CA, USA). Neutrophils were identified by their specific side scatter and forward scatter signals.

\section{Multiplex analysis}

Plasma from COPD patients and healthy age-matched controls were obtained from blood anti-coagulated with EDTA after immediate centrifugation $\left(2000 \mathrm{~g}\right.$ at $4{ }^{\circ} \mathrm{C}$ for $10 \mathrm{~min}$ ) and were stored at $-80^{\circ} \mathrm{C}$ until analysis. Concentrations of cytokines were determined by applying the Luminex platform as has been described before [24].

\section{Statistical analysis}

Statistical analysis of 2D-DIGE spot intensity was performed using DeCyder 7.0 BVA or EDA software (GE Healthcare, Uppsala, Sweden). Other statistical analyses were performed if appropriate using either an independent sample $t$ tests or an ANOVA with statistical software package IBM SPSS 20.

\section{Results}

\section{Patient characteristics}

In total, 41 at inclusion stable COPD patients and 7 healthy age-matched controls were included in this study. Fourteen COPD patients were currents smokers, whereas 27 of the COPD patients were ex-smokers. Four of the healthy controls were never smokers and 3 were ex-smokers. Details of the COPD patients and the controls are described in Table 1. It is important to emphasize that this study was set up to identify phenotypes within our group of stable COPD patients and not to study differences between COPD patients and healthy individuals. No statistical differences were found for age, BMI or hsCRP; whereas the FEV1 and the FEV1/FVC
Table 1 Patient characteristics

\begin{tabular}{llll}
\hline Characteristics & $\begin{array}{l}\text { Controls } \\
(N=7)\end{array}$ & $\begin{array}{l}\text { COPD } \\
(N=41)\end{array}$ & Statistics \\
\hline $\begin{array}{l}\text { Age, yrs } \\
\text { Gender }\end{array}$ & $60 \pm 6$ & $60 \pm 8$ & 0.929 \\
$\quad$ Male & 5 & 30 & \\
$\quad$ Female & 2 & 11 & \\
FEV1, L & $3.4 \pm 1.0$ & $1.6 \pm 1.0$ & $<0.001$ \\
FEV1, \% predicted & $109 \pm 21$ & $50 \pm 26$ & $<0.001$ \\
FEV1/FVC ratio & $77 \pm 4$ & $41 \pm 13$ & $<0.001$ \\
GOLD & & & \\
$\quad$ I & & 8 & \\
II & & 8 & \\
II & & 12 & \\
IV & & 13 &
\end{tabular}

MRC dyspnoe scale

$\begin{array}{lll}0 & 7 & 1 \\ 1 & & 10 \\ 2 & 12 \\ \geq 3 & 18\end{array}$

Smoking status

Current smoker 14

$\begin{array}{lll}\text { Ex-smoker } & 3 & 27\end{array}$

Never smoker $\quad 4$

$\mathrm{BMl}, \mathrm{kg} / \mathrm{m} 2 \quad 24 \pm 1.4 \quad 24 \pm 3.3 \quad 0.790$

$\begin{array}{llll}\text { hsCRP } & 3.8 \pm 5.4 & 4.6 \pm 6.9 & 0.765\end{array}$

$\begin{array}{llll}\text { Leukocyte count } & 6.2 \pm 1.9 & 7.7 \pm 1.8 & 0.052\end{array}$

Continues data are shown as mean \pm SD

FEV1 Forced Expiratory Volume 1, FVC Forced Vital Capacity, MRC Medical Research Council, GOLD Global Initiative for Chronic Obstructive Pulmonary Disease, $B M I$ Body mass index 
were statistically different between the COPD patients and the controls. Although the leukocyte counts of the COPD patients were not significantly different from the controls, the COPD patients have a higher leukocyte count than the controls $(p=0.05)$. This could implicate that there is an ongoing but low systemic inflammation in the COPD patients.

\section{D-DIGE analysis of peripheral neutrophils from controls and COPD patients}

We performed 2D-DIGE with peripheral neutrophils isolated from peripheral blood of healthy age matched controls and COPD patients. All protein samples were labelled with CyDye and separated by 2D-DIGE in different experiments. Upon analysis $1200-2400$ protein spots were identified by the DeCyder 7.0 software. Here a volume filter exclusion was used of 30000 in the Difference In-gel Analysis (DIA) software. The individual spot maps were matched in the Biological Variation Analysis (BVA) Software. We matched 2058 protein spots, of which 875 proteins were present in $>70 \%$ of the spot maps. Statistical analysis between healthy age-matched controls and COPD patients showed 21 proteins spots that were at least 1.5 fold differentially regulated with a $p<0.05$ (Fig. 2). Based on these 21 differentially regulated proteins the peripheral neutrophil spot maps from COPD patients could be separated from healthy age-matched controls by principal component analysis (PCA) (Fig. 3).
Hierarchical clustering of COPD and healthy control samples based on differential protein expression We observed differential protein expression in peripheral blood neutrophils between COPD patients and healthy age-matched controls using 2D-DIGE. We combined all differentially regulated proteins using the EDA in the DeCyder 7.0 software package and performed a hierarchical clustering analysis. Based on the 21 differentially expressed proteins we observed two groups in this way (Fig. 4a). COPD group 1 consists of a mix of healthy agematched control and COPD spot maps, whereas COPD group 2 comprised solely COPD spot maps. The COPD patients which were mixed with the healthy age-matched controls (COPD group 1) in the hierarchical clustering were indicated (blue dots) in the PCA analysis of the 21 differentially expressed proteins (Fig. 4b).

\section{No differences in clinical parameters between COPD group 1 and COPD group 2}

The hierarchical clustering showed a group that resembled neutrophils of healthy age-matched controls (COPD group 1) and a distinct group of COPD patients (COPD group 2) based on their differential protein expression. When we compared the lung function data (FEV1, FEV1/ FVC) between COPD patients in group 1 with the patients in group 2 there were no significant differences (Table 2). Therefore, the difference in peripheral neutrophil proteome identified by hierarchical clustering of spot maps did

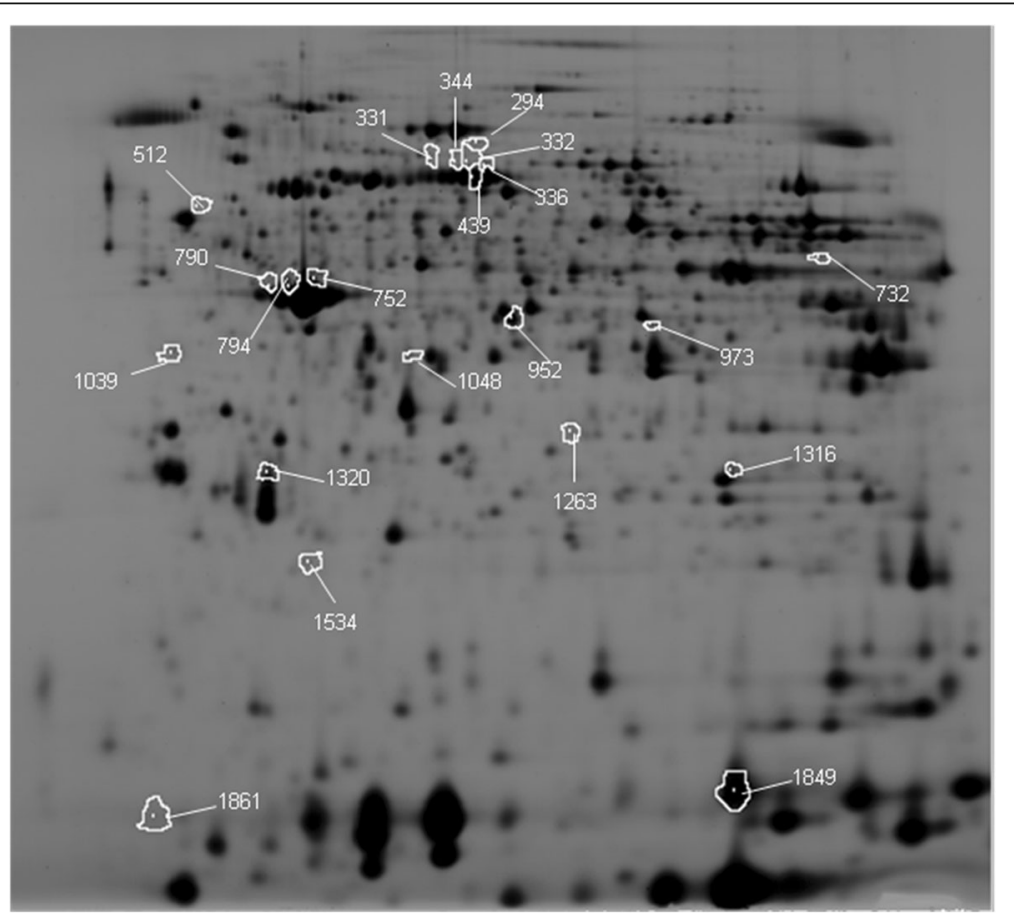

Fig. 2 2D-DIGE gel with the 21 differentially expressed proteins. Protein samples were focused on $24 \mathrm{~cm}$ pH3-10NL IEF strips and separated by $12 \%$ SDS-PAGE. The indicated spots represent the differentially regulated proteins identified by Decyder 7.0 analysis software 


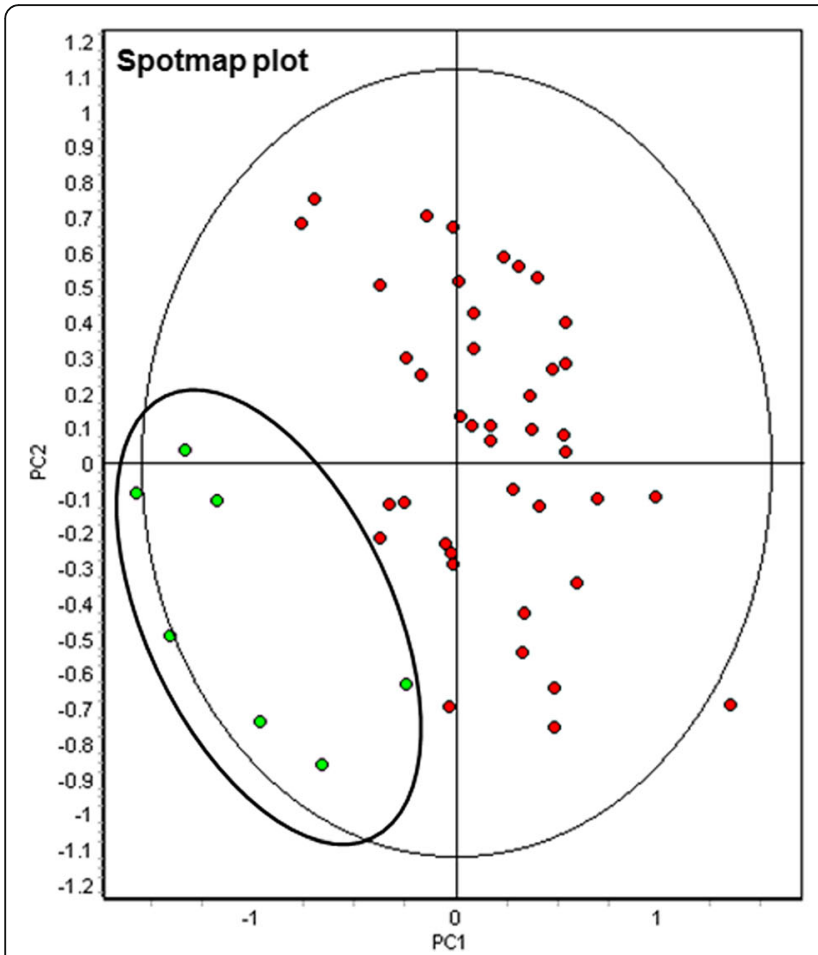

- COPD

- Control

Fig. 3 COPD spot maps were discriminative in a principal component analysis. Data of the 21 significant differentially regulated proteins (blue spots in the loading plot) in the Biological Variation Analysis (BVA) of peripheral neutrophils from COPD patients were imported in the extended data analysis (EDA) software. Principal component analysis (PCA) was performed on 41 COPD (red dots) and 7 age-matched control (green dots) spot maps

not correspond to the current classification of COPD based on FEV1 and FEV1/FVC. Also the hsCRP values and the total leukocyte counts were not significantly different between the two COPD groups (Table 2). Other clinical parameters are described in Table 2; these were also not significantly different between the two groups of COPD patients.

\section{Single activation markers on peripheral neutrophils are not significantly different between COPD group 1 and COPD group 2}

Although the neutrophils proteome was different between the two COPD groups; the expression of several activation markers were not significantly different (Table 3 and Fig. 5). The expression was measured on native nonactivated neutrophils. The activation markers Mac-1, CD66b and CXCR1 were similar between the two groups. Although the active FcyRII appeared to be higher in COPD group 2, it did not reach statistical significance.

Differences in cytokine levels between COPD group 1 and COPD group 2

We measured the levels of a number of cytokines but only a few were significantly different between the two COPD groups or between COPD and healthy age-matched controls (Fig. 6). The cytokine IL13 and the chemokines
CCL11 and CXCL8 were significantly different between COPD group 1 and 2 (Fig. 6b-d), whereas IL10 and CXCL8 (Figs. 4d, 6a) were significantly different between COPD group 2 and the healthy age-matched controls. The cytokines CCL11, chemerin and resistin (Fig. 6c, e-f) were different between COPD group 1 and the healthy age-matched controls.

\section{Reduced ROS production in COPD group 2}

The peripheral neutrophils from COPD group 2 had lower respiratory burst (ROS production) compared to the neutrophils from COPD group 1 (Fig. $7 \mathrm{a}-\mathrm{b}$ ). This was also the case for eosinophils (Fig. 7c-d) and monocytes (Fig. 7e-f). The respiratory burst of peripheral neutrophils after fMLF stimulation in controls was higher compared to COPD group 2 and lower compared to COPD group 1 (Fig. 7a-b).

\section{Discussion}

It has been well accepted that there is only a very poor relation between the GOLD stages and clinical manifestations such as symptoms and the health status of COPD patients $[5,6]$. COPD is a heterogeneous disease that is characterized by both pulmonary and extra-pulmonary manifestations and the GOLD classification does not include the extra-pulmonary components of this disease. 


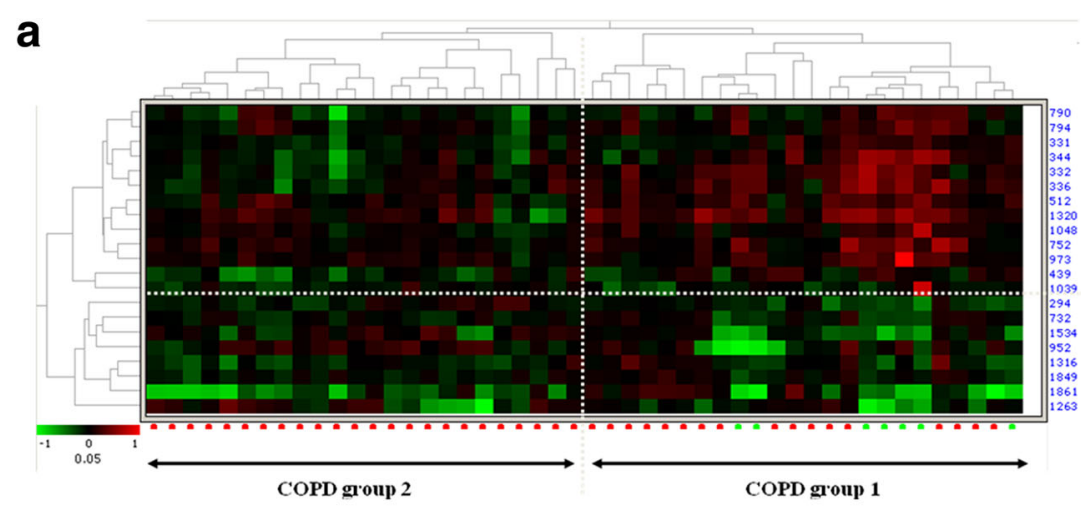

b

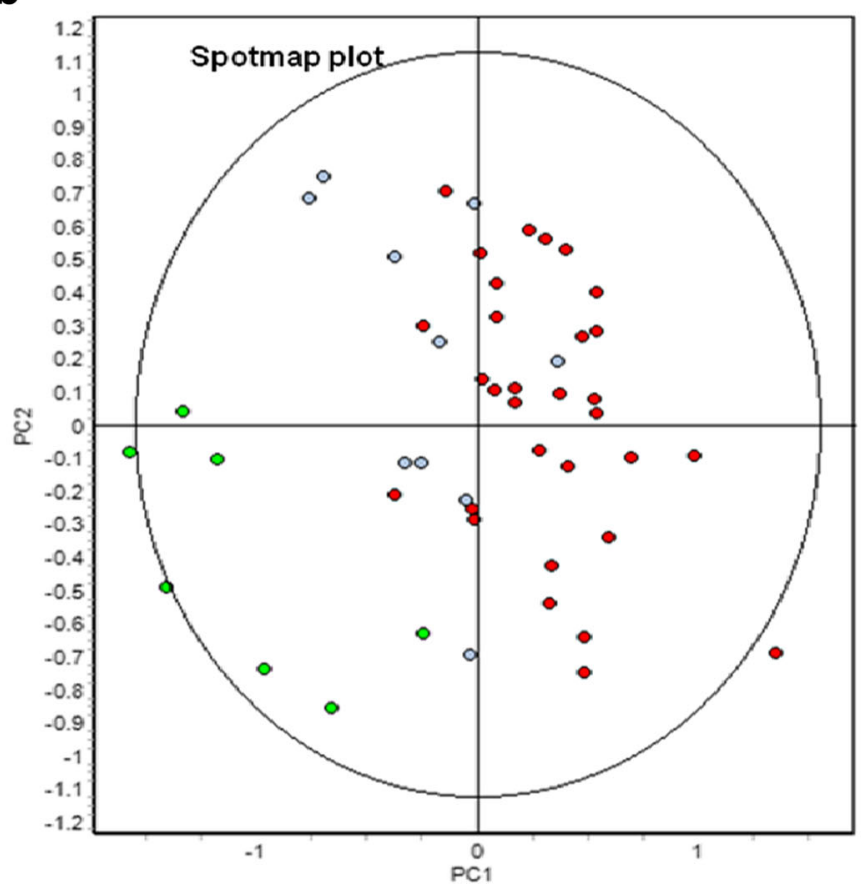

- COPD group 1

- COPD group 2

- Control

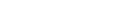


Table 2 Clinical data of COPD group 1 and COPD group 2

\begin{tabular}{llll}
\hline Clinical parameters & $\begin{array}{l}\text { COPD group 1 } \\
(N=17)\end{array}$ & $\begin{array}{l}\text { COPD group 2 } \\
(N=24)\end{array}$ & Statistics \\
\hline Age, yrs & $59 \pm 6$ & $61 \pm 9$ & 0.367 \\
FEV1, L & $1.89 \pm 1.27$ & $1.40 \pm 0.69$ & 0.167 \\
FEV1, \% predicted & $56 \pm 30$ & $46 \pm 22$ & 0.259 \\
FEV1/FVC ratio & $44 \pm 15$ & $39 \pm 12$ & 0.214 \\
Pack years & $46 \pm 18$ & $38 \pm 14$ & 0.160 \\
DLCO & $56 \pm 20$ & $60 \pm 21$ & 0.531 \\
P15, HU & $-946 \pm 23$ & $-953 \pm 22$ & 0.392 \\
6MWD, m & $472 \pm 106$ & $476 \pm 131$ & 0.904 \\
Pack years & $46 \pm 18$ & $38 \pm 14$ & 0.160 \\
MRC dyspnoe scale & $2.2 \pm 1.1$ & $2.6 \pm 1.4$ & 0.414 \\
CCQ total score & $2.1 \pm 1.2$ & $1.9 \pm 1.1$ & 0.696 \\
SGRQ total score & $44 \pm 19$ & $44 \pm 17$ & 0.899 \\
BODE index & $3.1 \pm 2.7$ & $3.4 \pm 2.5$ & 0.718 \\
hsCRP & $4.3 \pm 5.4$ & $4.9 \pm 7.8$ & 0.779 \\
Leukocyte count & $7.7 \pm 1.6$ & $7.7 \pm 2.0$ & 0.931 \\
\hline FEV1 Force Expiar
\end{tabular}

FEV1 Forced Expiratory Volume 1, FVC Forced Vital Capacity, DLCO Diffusion capacity of the lung for carbon monoxide, $P 1515$ th percentile, $H U$ hounsfield unit, 6MWD 6 min walking distance, CCQ Clinical COPD Questionnaire, SGRQ St. George's Respiratory Questionnaire

There is a clear distinction between the neutrophil proteome of the healthy age-matched controls and the COPD patients, albeit not the focus of this study (Fig. 3). Our data replicate our earlier results showing similar differences [25] in spot maps of neutrophils

Table 3 The activation markers on (unstimulated) peripheral neutrophils between COPD group 1 and COPD group 2

\begin{tabular}{llll}
\hline Activation markers & $\begin{array}{l}\text { COPD group } 1 \\
(N=17)\end{array}$ & $\begin{array}{l}\text { COPD group 2 } \\
(N=22)\end{array}$ & Statistics \\
MFI & Mean \pm SD & Mean \pm SD & \\
\hline CD11b & $85 \pm 36$ & $78 \pm 64$ & 0.699 \\
CD18 & $96 \pm 67$ & $80 \pm 31$ & 0.371 \\
CD64 & $38 \pm 65$ & $27 \pm 31$ & 0.493 \\
CD66b & $75 \pm 36$ & $78 \pm 34$ & 0.762 \\
Active FcyRII & $65 \pm 68$ & $120 \pm 239$ & 0.367 \\
CD32 & $214 \pm 52$ & $233 \pm 34$ & 0.136 \\
CXCR1 & $190 \pm 58$ & $188 \pm 49$ & 0.936 \\
CD62L & $255 \pm 234$ & $194 \pm 75$ & 0.317 \\
CD45 & $10 \pm 4.86$ & $11 \pm 4.12$ & 0.541 \\
CXCR2 & $64 \pm 17$ & $67 \pm 30$ & 0.920 \\
CD35 & $31 \pm 15$ & $32 \pm 21$ & 0.310 \\
CD15 & $958 \pm 363$ & $1171 \pm 519$ & 0.920 \\
CD63 & $4.02 \pm 0.78$ & $4.46 \pm 1.42$ & 0.920 \\
CD44 & $541 \pm 114$ & $579 \pm 163$ & 0.152 \\
N29 & $17 \pm 4$ & $19 \pm 11$ & 0.920 \\
\hline
\end{tabular}

MFI median fluorescence intensity, SD standard deviation from a small group of COPD patients and age-matched controls.

A limitation in our study is that about $60 \%$ of the healthy age-matched controls were never smokers; whereas COPD is a smoking related disease. In our earlier study [25] spot maps from COPD patients were compared with control spot maps of either ex-smokers or nonsmokers in a PCA and still showed clustering of COPD spot maps apart from the control spot maps. Apparently, COPD specific signals could be identified irrespective of the smoking habits of the control groups.

Using the differentially expressed proteins in a hierarchial clustering, we could identify two different clusters. One cluster only existed of COPD patients while the second cluster coexisted of both COPD patients and agematched controls (Fig. 4a). The existence of the two COPD groups identified by the 2D-DIGE approach suggest that peripheral neutrophils were differentially affected by systemic inflammatory processes in vivo, probably by different combinations of pro-and anti-inflammatory mediators.

We sought to find differences in clinical and immunological parameters between the two COPD groups. We were unable to find statistical differences in lung function (FEV1, FEV1/FVC) (Table 2). Therefore, it is unlikely that the lung function was related to the proteome of the peripheral neutrophils. This fits with other studies including ECLIPSE $[26,27]$ that failed to demonstrate a correlation between systemic inflammation and lung function in at inclusion stable COPD patients. Interestingly hsCRP, which is known as a marker for systemic inflammation, was not statistically different between the two COPD groups and/or GOLD stages. This is also in line with previous studies $[28,29]$. These data add to a growing understanding that if systemic inflammation is an important constituent of the pathogenesis of stable COPD, this process cannot be adequately determined by either GOLD classification nor changes in hsCRP levels. In contrast to stable COPD, the situation with exacerbations is different as high CRP levels have been found in COPD patients under these conditions [30-32].

Our data regarding the absence of differences in expression of CD11b and CXCR1 on neutrophils (Table 3) contrast findings published by others [33, 34]. Although the COPD patients in the studies of Yamagata et al. [34] and Noguera et al. [33] were stable, the expression of CD11b and CXCR1 on neutrophils was measured on isolated neutrophils. Kuijpers et al. [35] have shown that isolation induce activation of neutrophils, which is likely more pronounced on primed cells such as found in our COPD patients (see below). Others have also been unsuccessful in finding enhanced levels of hsCRP in stable COPD patients $[28,29]$. Therefore, it seems that a low grade systemic inflammation present in stable COPD 

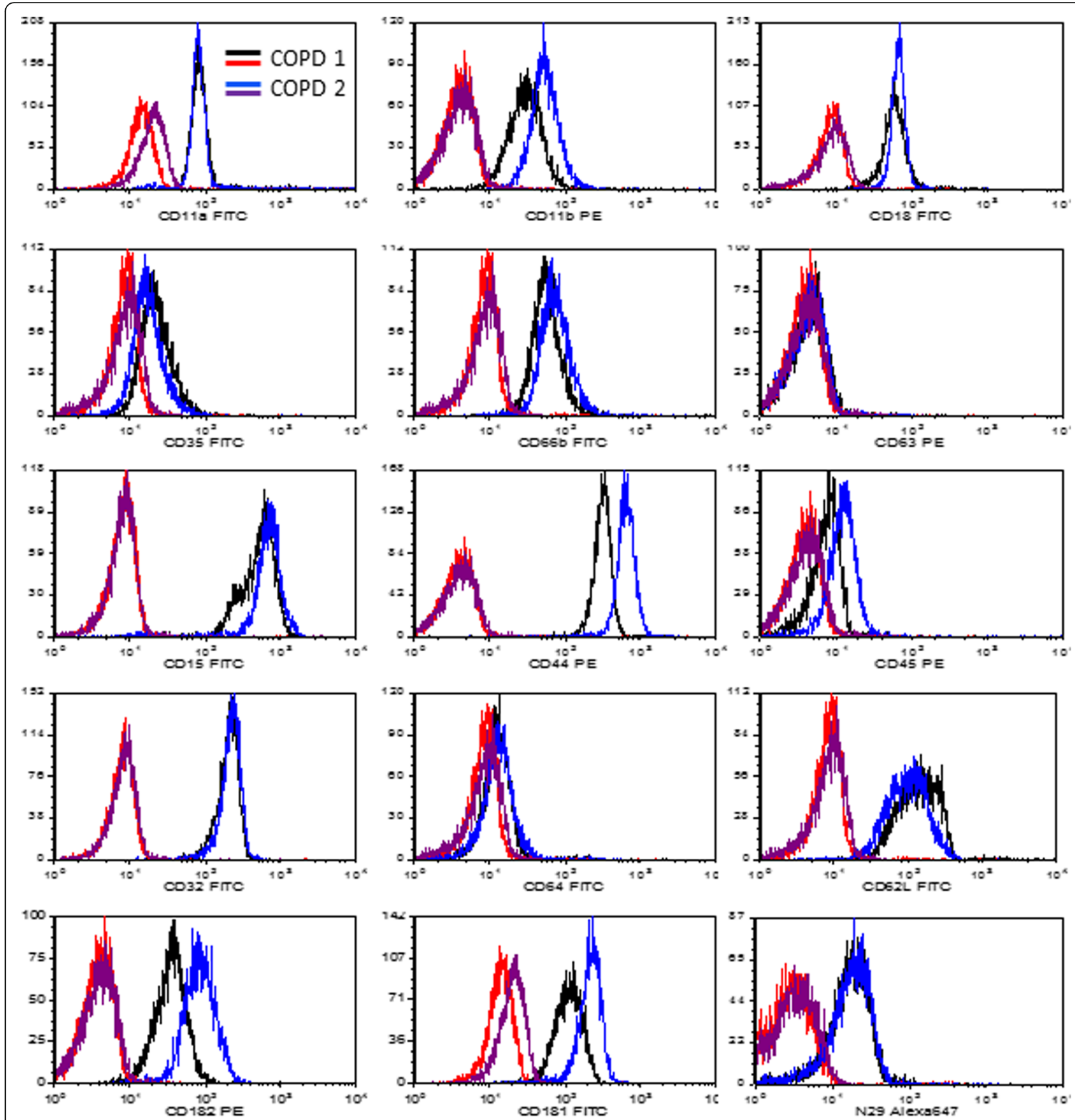

Fig. 5 Histogram overlays of the expression of all used markers on neutrophils from COPD group 1 and COPD group 2. Representative example of the subtle changes in expression of different markers on neutrophils isolated from patient blood of the different COPD groups. Isotype controls are shown in red and purple for cells of COPD 1 and COPD 2, respectively. For statistics see Table 3

patients did not lead to an increased expression of CD11b, CXCR1 or hsCRP.

The systemic inflammation in our COPD cohort was associated with minor differences in the presence of systemic mediators (Fig. 6). We first focused on changes in serum TNF $\alpha$ as differences in the presence of this cytokine has been found previously [17, 36, 37]. We failed to detect differences in levels of TNF $\alpha$ between the controls and the COPD patients which were also not found in ECLIPSE. In this study TNFo appeared to be primarily a marker of smoking and not of COPD [27]. In addition, we found no difference in TNF $\alpha$ between the two COPD groups (data not shown). These data question an important role of systemic TNF $\alpha$ in the pathogenesis of stable COPD. This conclusion is supported by our previous study that [25] showed that the proteomes of peripheral 

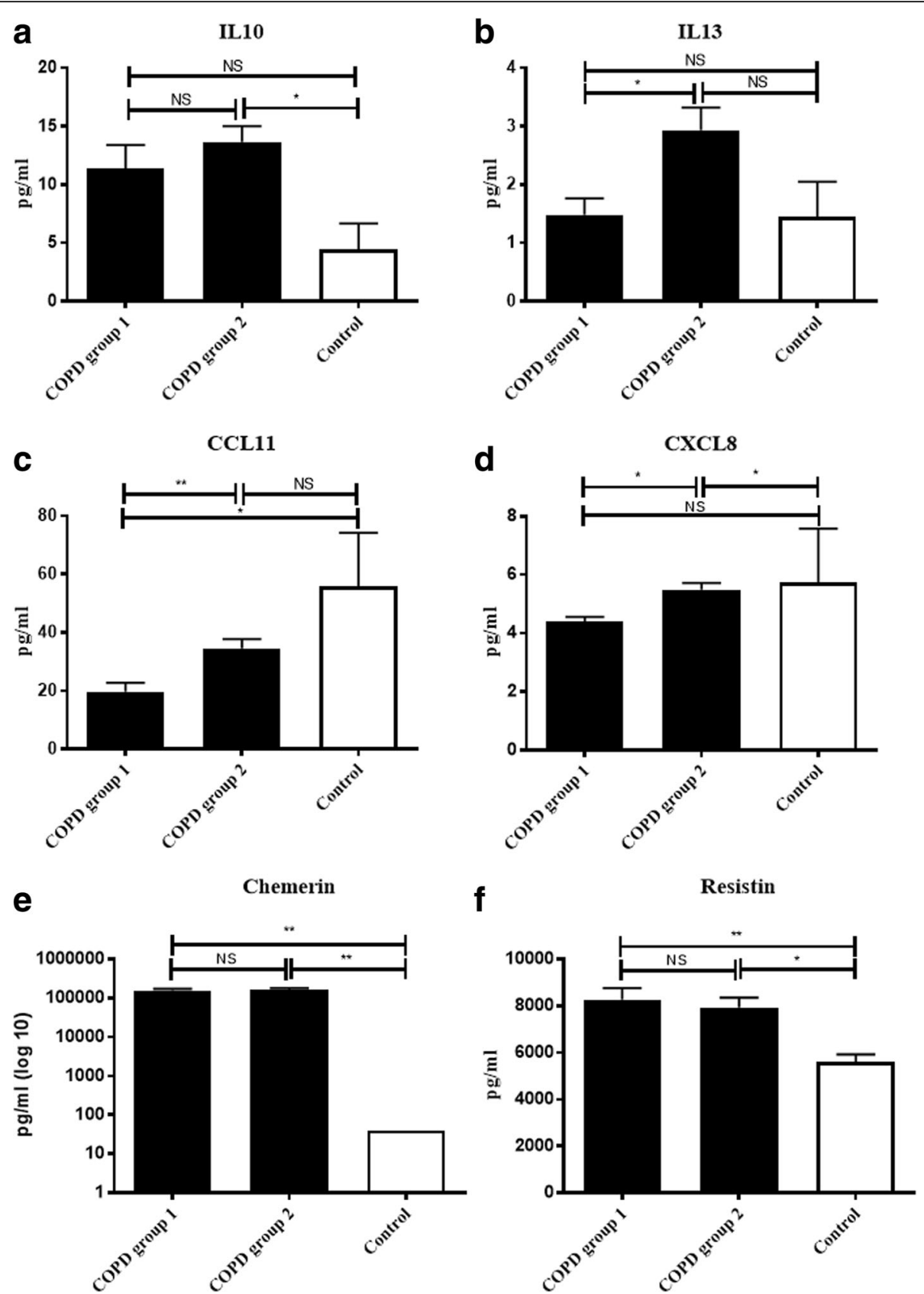

Fig. 6 Cytokine differences between the two COPD groups and the age-matched controls. Plots with the mean plasma levels of IL10, IL13, CCL11, CXCL8, Chemerin and Resistin (a-f) in age-matched controls $(n=6)$, COPD patient group $1(n=17)$ and COPD patient group 2 ( $n=24)$. Cytokine levels are expressed as Mean $\pm \mathrm{SEM}$. An ANOVA was used to perform statistics $\left({ }^{*} p<0.05 ;{ }^{* *} p<0.01 \mathrm{NS}=\right.$ not significant)

neutrophils of COPD patients were not similar to peripheral neutrophils that were stimulated in vitro by TNFa. The only differences in cytokine levels between the two COPD groups were found for IL13 and chemokines CCL11/eotaxin, CXCL8/IL-8 (Fig. 6b-d). This might indicate that both the systemic eosinophils (IL-13/Eotaxin) as well as the systemic neutrophil (CXCL8/IL-8) compartment are affected in stable COPD without changes in the aforementioned characteristics of the cells.
The above mentioned data prompted us to analyse more subtle changes in granulocyte physiology and analysed the functionality of the cells in the context of activation of the respiratory burst. Neutrophils carefully isolated from normal control individuals are characterized by a low fMLF-induced respiratory burst as this response needs priming by agonists such as PAF that by themselves are poor activators of this response. The relative fMLF response in isolated cells compared to 
a

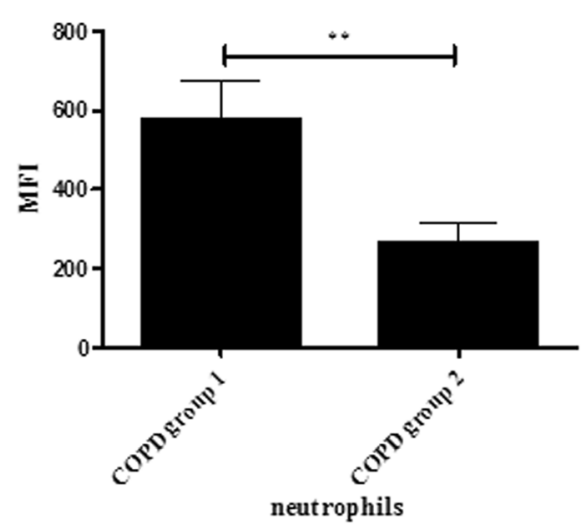

C

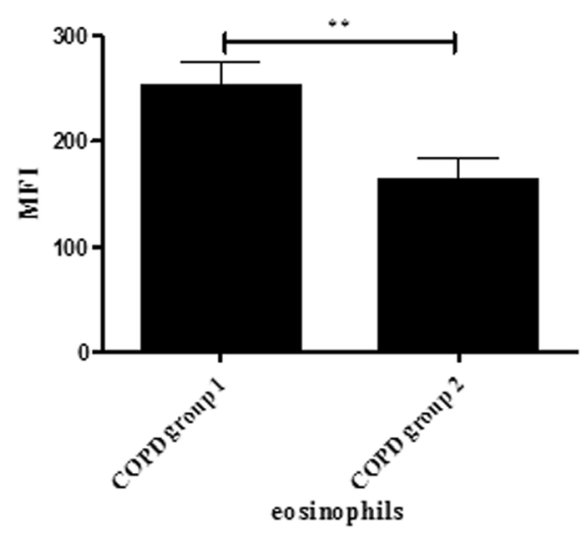

e fMILF induced burst

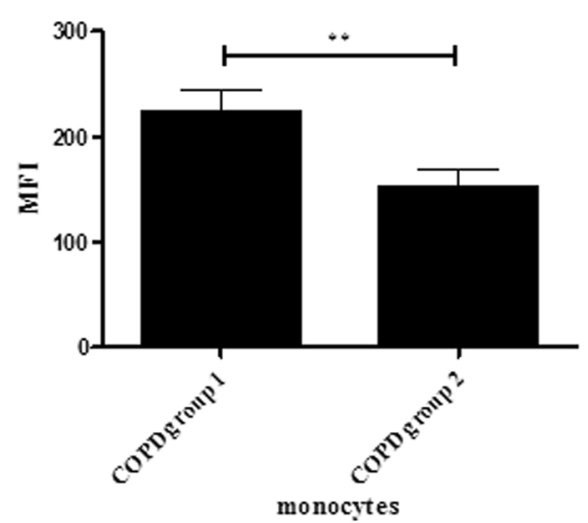

b PAF fILF induced burst

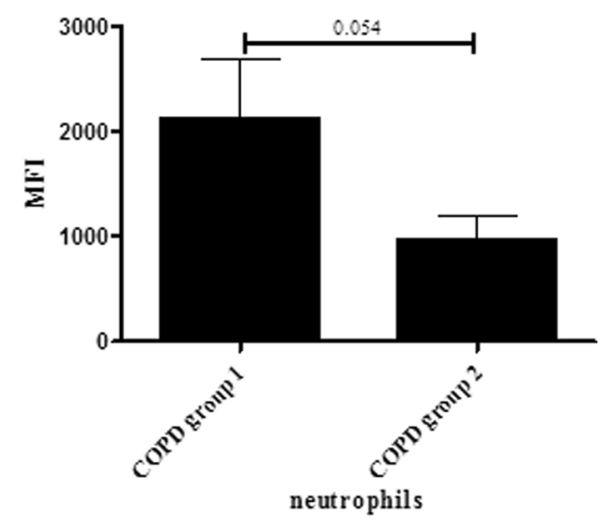

d

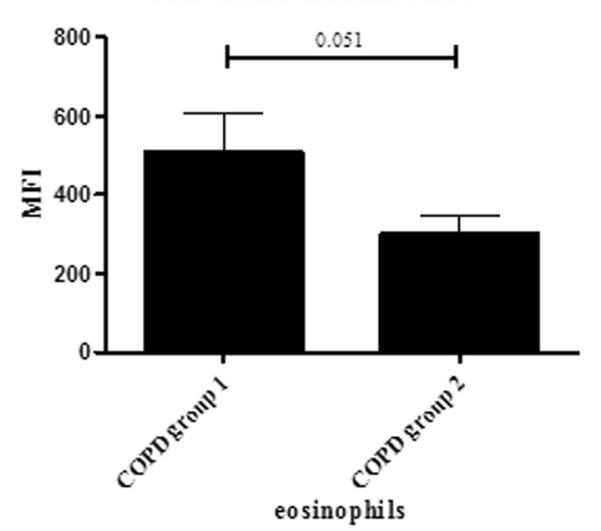

$\mathbf{f}$

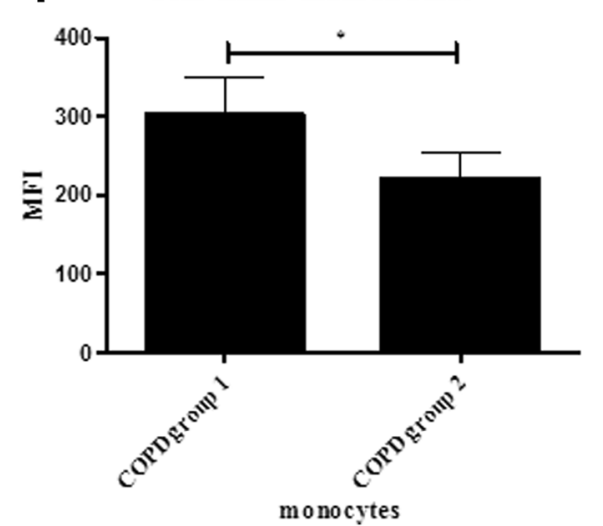

Fig. 7 The respiratory burst (ROS production) assay. Leukocytes (2.0 10^6 cells $/ \mathrm{ml})$ of age-matched controls $(n=12)$, COPD patient groups 1 ( $n=17)$ and COPD patient group $2(n=19)$ were pre-incubated in the presence or absence of PAF $\left(10^{-6} \mathrm{M}\right)$; loaded with DHR 123 for 5 min and stimulated with fMLF (a-f) for 15 min at $37^{\circ} \mathrm{C}$. Production of ROS was measured by oxidation of intracellular DHR 123 and measured using flow cytometry (Mean \pm SEM). An independent $t$-test $\left({ }^{* *}=p<0.01,{ }^{*}=p<0.05\right)$ was used to perform statistical analysis

PAF primed cells is a measure of neutrophil priming [38]. The respiratory burst (ROS production) of the peripheral neutrophils of the two COPD groups were significantly different (Fig. 7a-b). The fMLF-induced ROS production of peripheral neutrophils from COPD group 1 patients tended to be higher compared to controls; whereas the ROS production of peripheral neutrophils from COPD group 2 patients was lower. This difference in functionality after fMLF stimulation between COPD group 1 and 2 was not only present in peripheral neutrophils but also in 
eosinophils and monocytes (Fig. 7c-f). These data fit the hypothesis that COPD group 1 is characterized by the presence of systemic neutrophils with a primed phenotype (higher ROS production compared to healthy controls) and COPD group 2 is characterized by cells with a hyporesponsive phenotype. The underlying mechanisms might be that COPD group 2 has systemic neutrophils with a hypo-responsive phenotype, because hyper-responsive/ primed cells have migrated to the tissues leaving behind more refractory cells in the circulation. However, this difference seen in the functionality of the cells did not lead to differences in clinical manifestations, which were measured in this study. More clinical data, better and more subtle differences in innate immune cells, larger cohorts of COPD patients and the identification of the 21 differentially expressed proteins will probably improve the understanding of different COPD phenotypes and the differences found in the functionality of peripheral neutrophils between the two groups.

\section{Conclusion}

We identified a distinct group of COPD patients, who were different from healthy age-matched controls and other COPD patients based on the proteome of peripheral neutrophils. Lung function was not different between the two COPD patient groups. However, the ROS production of peripheral neutrophils was different in COPD group 1 compared to COPD group 2. These data are consistent with the hypothesis that COPD patients are characterized by subtle differences in systemic inflammation that cannot be identified by classical markers. These differences are, however, apparent when the functionality of the cells is studied. Therefore, future studies on targeting systemic inflammation in stable COPD should focus on these subtle difference and this difference should not rely only on the classical markers such as individual cytokines, acute phase proteins or single activation markers.

\section{Abbreviations \\ BAL: Bronchoalveolar lavage; BVA: Biological variation analysis; CD: Cluster of differentiation; COPD: Chronic obstructive pulmonary disease; Cy: Cyanine; DHR: Dihydrorhodamine; DIA: Difference in-gel analysis; DIGE: Difference gel electrophoresis; EDA: Enhanced data analysis; FEV1: Forced expiratory volume in 1 second; fMLF: Formyl-methionyl-leucyl-phenylalanine; FVC: Forced vital capacity; GM-CSF: Granulocyte-macrophage colony-stimulating factor; GOLD: Global initiative for chronic obstructive pulmonary disease; hsCRP: High sensitiveC-reactive protein; IL: Interleukin; PAF: Platelet-activating factor; PBS: Phosphate-buffered saline; ROS: Reactive oxygen species; TNF: Tumour necrosis factor}

\section{Acknowledgements}

No Acknowledgements.

\section{Funding}

NCT00807469: T1-108 grant from Top Institute Pharma, with partners Nycomed, GlaxoSmithKline, University Medical Center Groningen (UMCG), and University of Groningen (RUG).
Availability of data and materials

Please contact authors for data requests.

\section{Authors' contributions}

Design and conduct of the study: LK, JWL, NH, ALTL, SH. Data collection and analysis: ALTL, SH, CA, JL, VK, SSE. Data interpretation: SJMH, ATLTL, NTH, LK, JWJ, JL VK Manuscript writing: ALTL, LK. All authors have read and approved the final version of the article.

\section{Competing interests}

The authors declare that they have no competing interests.

\section{Consent for publication}

Not appicable.

Ethics approval and consent to participate

Data were collected from a study performed in Groningen and Utrecht, the Netherlands (Clinicaltrials.gov: NCT00807469). All participating subjects gave peripheral blood. All measurements were obtained by using standardized protocols. All studies and sample collection were approved by the medical ethics committees of University Medical Centers Groningen (UMCG) and Utrecht (UMCU), the Netherlands. All participants gave their written informed consent.

\section{Publisher's Note}

Springer Nature remains neutral with regard to jurisdictional claims in published maps and institutional affiliations.

\section{Author details}

${ }^{1}$ Departments of Respiratory Medicine, University Medical Center Utrecht, Utrecht, The Netherlands. ${ }^{2}$ Departments of Respiratory Medicine, University Medical Center Groningen, Groningen, The Netherlands. ${ }^{3}$ Department Respiratory Medicine and Laboratory of Translational Immunology, University Medical Center Utrecht, Heidelberglaan 100, 3583CX Utrecht, The Netherlands.

Received: 8 November 2016 Accepted: 16 May 2017

Published online: 22 May 2017

\section{References}

1. Celli BR, MacNee W, Force AET. Standards for the diagnosis and treatment of patients with COPD: a summary of the ATS/ERS position paper. Eur Respir J. 2004;23(6):932-46.

2. Decramer M, Janssens W, Miravitlles M. Chronic obstructive pulmonary disease. Lancet. 2012;379(9823):1341-51.

3. Lapperre TS, Snoeck-Stroband JB, Gosman MM, et al. Dissociation of lung function and airway inflammation in chronic obstructive pulmonary disease. Am J Respir Crit Care Med. 2004;170(5):499-504.

4. Rabe KF, Hurd S, Anzueto A, et al. Global strategy for the diagnosis, management, and prevention of chronic obstructive pulmonary disease: GOLD executive summary. Am J Respir Crit Care Med. 2007;176(6):532-55.

5. Antonelli-Incalzi R, Imperiale C, Bellia V, et al. Do GOLD stages of COPD severity really correspond to differences in health status? Eur Respir J. 2003;22(3):444-9.

6. Cooper CB. The connection between chronic obstructive pulmonary disease symptoms and hyperinflation and its impact on exercise and function. Am J Med. 2006;119(10 Suppl 1):21-31.

7. Borrill ZL, Roy K, Singh D. Exhaled breath condensate biomarkers in COPD. Eur Respir J. 2008;32(2):472-86.

8. Bhattacharya S, Srisuma S, Demeo DL, et al. Molecular biomarkers for quantitative and discrete COPD phenotypes. Am J Respir Cell Mol Biol. 2009;40(3):359-67.

9. Kelsen SG, Duan $X$, Ji $R$, et al. Cigarette smoke induces an unfolded protein response in the human lung: a proteomic approach. Am J Respir Cell Mol Biol. 2008;38(5):541-50.

10. Ohlmeier $\mathrm{S}$, Vuolanto M, Toljamo T, et al. Proteomics of human lung tissue identifies surfactant protein $\mathrm{A}$ as a marker of chronic obstructive pulmonary disease. J Proteome Res. 2008;7(12):5125-32.

11. Gray RD, MacGregor G, Noble D, et al. Sputum proteomics in inflammatory and suppurative respiratory diseases. Am J Respir Crit Care Med. 2008;178(5):444-52. 
12. Bandow JE, Baker JD, Berth M, et al. Improved image analysis workflow for 2-D gels enables large-scale 2-D gel-based proteomics studies-COPD biomarker discovery study. Proteomics. 2008;8(15):3030-41.

13. Bozinovski $\mathrm{S}$, Hutchinson $\mathrm{A}$, Thompson $\mathrm{M}$, et al. Serum amyloid a is a biomarker of acute exacerbations of chronic obstructive pulmonary disease. Am J Respir Crit Care Med. 2008;177(3):269-78.

14. Bowler RP, Canham ME, Ellison MC. Surface enhanced laser desorption/ ionization (SELDI) time-of-flight mass spectrometry to identify patients with chronic obstructive pulmonary disease. Copd. 2006;3(1):41-50.

15. Merkel D, Rist W, Seither P, et al. Proteomic study of human bronchoalveolar lavage fluids from smokers with chronic obstructive pulmonary disease by combining surface-enhanced laser desorption/ ionization-mass spectrometry profiling with mass spectrometric protein identification. Proteomics. 2005;5(11):2972-80.

16. Hogg JC. Pathophysiology of airflow limitation in chronic obstructive pulmonary disease. Lancet. 2004;364(9435):709-21.

17. Di Francia M, Barbier D, Mege $J$, et al. Tumor necrosis factor-alpha levels and weight loss in chronic obstructive pulmonary disease. Am J Respir Crit Care Med. 1994;150(5 Pt 1):1453-5.

18. Schols AM, Buurman WA, Staal van den Brekel AJ, et al. Evidence for a relation between metabolic derangements and increased levels of inflammatory mediators in a subgroup of patients with chronic obstructive pulmonary disease. Thorax. 1996;51(8):819-24

19. Oudijk EJ, Nijhuis EH, Zwank MD, et al. Systemic inflammation in COPD visualised by gene profiling in peripheral blood neutrophils. Thorax. 2005;60(7):538-44

20. Oudijk EJ, Lo Tam Loi AT, Langereis JD, et al. Functional antagonism by GMCSF on TNF-alpha-induced CD83 expression in human neutrophils. Mol Immunol. 2008;46(1):91-6.

21. Global strategy for the diagnosis, management, and prevention of chronic obstructive pulmonary disease. Available at: http://goldcopd.org/globalstrategy-diagnosis-management-prevention-copd-2016/

22. Tonge R, Shaw J, Middleton B, et al. Validation and development of fluorescence two-dimensional differential gel electrophoresis proteomics technology. Proteomics. 2001;1(3):377-96.

23. Koenderman $L$, Kanters $D$, Maesen $B$, et al. Monitoring of neutrophil priming in whole blood by antibodies isolated from a synthetic phage antibody library. J Leukoc Biol. 2000;68(1):58-64

24. de Jager W, Bourcier K, Rijkers GT, et al. Prerequisites for cytokine measurements in clinical trials with multiplex immunoassays. BMC Immunol. 2009;10:52

25. Langereis JD, Schweizer RC, Lammers JW, et al. A unique protein profile of peripheral neutrophils from COPD patients does not reflect cytokineinduced protein profiles of neutrophils in vitro. BMC Pulm Med. 2011;11:44.

26. Agusti A, Calverley PM, Celli B, et al. Characterisation of COPD heterogeneity in the ECLIPSE cohort. Respir Res. 2010;11:122

27. Agusti A, Edwards LD, Rennard SI, et al. Persistent systemic inflammation is associated with poor clinical outcomes in COPD: a novel phenotype. PLoS One. 2012;7(5):e37483.

28. Vestbo J, Prescott E, Almdal T, et al. Body mass, fat-free body mass, and prognosis in patients with chronic obstructive pulmonary disease from a random population sample: findings from the Copenhagen City Heart Study. Am J Respir Crit Care Med. 2006;173(1):79-83.

29. Man SF, Connett JE, Anthonisen NR, et al. C-reactive protein and mortality in mild to moderate chronic obstructive pulmonary disease. Thorax. 2006; 61(10):849-53.

30. Daniels JM, Schoorl M, Snijders D, et al. Procalcitonin vs C-reactive protein as predictive markers of response to antibiotic therapy in acute exacerbations of COPD. Chest. 2010;138(5):1108-15.

31. Hurst JR, Donaldson GC, Perera WR, et al. Use of plasma biomarkers at exacerbation of chronic obstructive pulmonary disease. Am J Respir Crit Care Med. 2006;174(8):867-74.

32. Karadeniz G, Polat $\mathrm{G}$, Senol G, et al. C-reactive protein measurements as a marker of the severity of chronic obstructive pulmonary disease exacerbations. Inflammation. 2013;36(4):948-53.

33. Noguera A, Sala E, Pons AR, et al. Expression of adhesion molecules during apoptosis of circulating neutrophils in COPD. Chest. 2004;125(5):1837-42.

34. Yamagata $T$, Sugiura H, Yokoyama $T$, et al. Overexpression of CD-11 b and CXCR1 on circulating neutrophils: its possible role in COPD. Chest. 2007; 132(3):890-9.
35. Kuijpers TW, Tool AT, van der Schoot CE, et al. Membrane surface antigen expression on neutrophils: a reappraisal of the use of surface markers for neutrophil activation. Blood. 1991;78(4):1105-11.

36. Takabatake $\mathrm{N}$, Nakamura $\mathrm{H}$, Abe $\mathrm{S}$, et al. The relationship between chronic hypoxemia and activation of the tumor necrosis factor-alpha system in patients with chronic obstructive pulmonary disease. Am J Respir Crit Care Med. 2000;161(4 Pt 1):1179-84.

37. Vernooy JH, Kucukaycan M, Jacobs JA, et al. Local and systemic inflammation in patients with chronic obstructive pulmonary disease: soluble tumor necrosis factor receptors are increased in sputum. Am J Respir Crit Care Med. 2002;166(9):1218-24.

38. Koenderman L, Yazdanbakhsh M, Roos D, Verhoeven AJ. Dual mechanisms in priming of the chemoattractant-induced respiratory burst in human granulocytes. A Ca2 +-dependent and a Ca2 +-independent route. J Immunol. 1989;142(2):623-8.

\section{Submit your next manuscript to BioMed Central and we will help you at every step:}

- We accept pre-submission inquiries

- Our selector tool helps you to find the most relevant journal

- We provide round the clock customer support

- Convenient online submission

- Thorough peer review

- Inclusion in PubMed and all major indexing services

- Maximum visibility for your research

Submit your manuscript at www.biomedcentral.com/submit 